\title{
Data Envelopment Analysis of Productivity Changes in Higher Education For-profit Enterprises Compared to Non-profits
}

\author{
G. Thomas Sav \\ Correspondence: G. Thomas Sav, Department of Economics, Raj Soin College of Business, Wright State \\ University, Ohio 45440, United States. Tel: 1-937-775-3070. E-mail: tom.sav@wright.edu
}

Received: May 13, 2012

Accepted: May 31, 2012

Online Published: July 31, 2012

doi:10.5539/ibr.v5n9p1

URL: http://dx.doi.org/10.5539/ibr.v5n9p1

\begin{abstract}
Data envelopment analysis is used to compare private for-profit colleges to publicly owned colleges in terms of their operating efficiency and productivity. Academic year 2005-09 panel data is used for two-year institutions in the U.S. Results indicate that for-profit efficiency exceeded that of public colleges. Malmquist index results show that colleges in both sectors increased managerial and scale efficiencies, but that both were hindered by technological regress to the extent that overall productivity declined. 2007-08 created efficiency declines across the board, but for-profits managed large technological gains that produced the only annual productivity improvement for either sector. The results are important for better understanding the increasing privatization of higher education through the entry of for-profit institutions and for understanding the inter-sector differential effects and responses to the global financial crisis.
\end{abstract}

Keywords: productivity, efficiency, data envelopment analysis, Malmquist, colleges, higher education

\section{Introduction}

This paper provides estimates of efficiency and productivity changes that have occurred among private for-profit colleges in comparison to publicly owned and operated colleges. Private and public sector estimates are the result of applying data envelopment analysis (DEA) to panel data covering the 2005-09 academic years for two-year degree granting colleges in the United States. DEA efficiencies and scale technologies are estimated annually and the Malmquist index is used to determine productivity changes along with its decomposed changes due to management and scale efficiency changes and technological changes. Based on the academic years under evaluation, the estimates are intended to provide potential insights into the differential effects of the financial crisis on the provision of higher education as pertaining to private for-profit relative to public colleges.

The need for this inquiry is twofold. First is the growing entry of for-profit institutions into higher education. That is occurring internationally and, in part, is driven by lower communication and regulatory barriers to distance or online education. However, in the U.S. the largest growth has occurred in the two-year college sector where for-profit college presence has increased from $12 \%$ to $32 \%$ of the institutions over the past two decades. Second, is the increasing focus on public management reform that has accelerated with the deficit and budgetary problems induced by the global financial crisis. That reform has also generated increasing interest in greater privatization of higher education. Thus, from both perspectives, there is a need for better understanding the extent to which there are differences, if any, in the operating efficiencies and productivities of private for-profit relative to publicly run higher education institutions. Based on what is believed to be a reasonably exhaustive literature search, this paper appears to be the first to apply DEA to longitudinal data in providing estimates in support of that need.

The next section of the paper presents a brief overview of DEA and a literature review as it has been applied to higher education. That is followed by an exposition of the DEA and Malmquist methodology employed in the paper, a section describing the data, a section pertaining to the empirical results, and then the concluding remarks.

\section{Literature Background}

DEA has become the standard nonparametric tool for evaluating the operating efficiency of individual producers. As a mathematical programming approach, it is due to the seminal work of Charnes, et al. (1978) and has wide applications to what is referred to as any collection of "decision making units" or DMUs. Applications have 
included inquiries into the efficiencies of government agencies, for-profit firms, and not-for-profit entities, including educational institutions (Cooper et al., 2004). For the DMU, an efficient unit that is "best" is determined and employed as an efficiency benchmark. A DMU is then inefficient if the benchmark uses less input to produce the same output or produces more output with the same input. Efficiency indexes or scores range from 0 to 1 or $100 \%$ efficient. Using longitudinal or panel data observations, the Malmquist (1953) index defined by Caves et al. (1982) can be employed to determine productivity changes over time. Indexes below unity represent productivity regress while those above unity demonstrate productivity gains. It is also possible to decompose total productivity change into that part due to technical changes, size or scale efficiency changes, and changes that can be attributed to management.

A literature search revealed that there are only three longitudinal or panel data studies of higher education using DEA. Based on cross section data, there appears to be another fourteen studies. Overall, these studies are relatively new and in number they pale in comparison to the hundreds of DEA applications to other industries. The bulk of that literature, as well as the methodological developments of DEA are well documented elsewhere, including, e.g., Cooper (2004), Cook and Zhu (2008), and Johnes (2004). For present purposes, the focus remains with the DEA studies applied to higher education.

The three panel data studies related to higher education are, by far, the new comers to the DEA higher education literature: the three appeared in 2007, 2008, and 2009. The major panel data thrust of each study is to estimate university productivity changes over time using the Malmquist index. Castano and Cabanda (2007) examine 59 Philippine universities over five academic years, 1999-2003. They find productivity changes ranging from approximately 0.93 to 1.30 and, therefore, some universities showing productivity regress of $7 \%$ and other showing productivity improvements of $30 \%$. The average productivity gain was on the order of only $0.2 \%$. Worthington and Lee (2008) study a smaller sample of 35 Australian universities over nearly the same academic years but include one more year for a total of 1998-2003. Over that six year period, Australian universities reportedly generated productivity changes in the narrower range of $-1.8 \%$ to $13 \%$. Relative to the Philippine sample, Australian universities experienced greater average mean productivity improvement of $3.3 \%$. The most recent study by Agasisti and Johnes (2009) covers four academic years 2001-04 and includes 57 Italian and 127 English universities. The study did not provide productivity ranges. The estimated mean university productivity gains for each country, however, significantly outstripped both the Philippine and Australian universities. The average productivity gains were $9.4 \%$ per annum in Italy and $8.5 \%$ per annum in England.

The remainder of the higher education DEA studies use cross sectional data and, therefore, are more limited in scope in that they provide efficiency estimates but cannot provide estimates of productivity changes. In addition, eight of the studies are focused at specific university departments or program offerings rather than the university as the DMU. For example, Beasley (1990) examines the efficiency of chemistry and physics departments within 52 United Kingdom universities in the 1986 (i.e., 1986-87) academic year. Beasley (1995) used the same data to offer extensions of his earlier work. Stern et al. (1994) apply DEA to 21 different departments for 1988 at the Ben Gurion University. The study by Cobert et al. (2000) is a 1997 cross section of 24 MBA programs in the U.S. Other investigations include a sample of 18 research units at the Helsinki school of economics (Korhonen et al., 2001), 118 university libraries in the U.S. (Reichmann, 2004), the efficiency of the central administration in 108 United Kingdom universities (Casu \& Thanassoulis, 2006), and more than 950 departments housed in 12 Austrian universities in both 2000-01 and 2001-02 academic years (Leitner et al., 2007). Given the diversity of these studies, it is not surprising that there exists a wide range of efficiency estimates; aside from the $100 \%$ efficiency scores, the minimum efficiency scores ranged from $18 \%$ to $92 \%$.

The other seven cross section studies utilize the university as opposed to the department as the DMU. The study by Ahn et al. (1988) sampled 161 U.S. doctoral granting universities for the 1984-85 academic year and found operating efficiency scores ranging from 0.62 to 1.0. In contrast, Breu et al. (1994) selection of the 25 top ranked 1992 U.S. national universities produced a minimum efficiency score of only $87 \%$. Athannassapoulos and Shale (1997) and Glass et al. (2006) report substantially different efficiency scores among their samples of United Kingdom universities; the range being 0.37-1.0 for 52 universities during the 1992 academic year and 0.14-1.0 for 98 universities operating in the 1996 academic year, respectively. According to Avkiran (2001), the 36 sampled Australian universities appear more efficient with a 0.82-1.0 efficiency range during 1995-96. A 1992-93 academic year study of Canadian universities was by McMillan and Chan (2006) provides an efficiency range of 0.55-1.0.

All of these studies use different variables to proxy outputs and inputs, use different academic years, and employ different modeling assumptions. Moreover, from an international perspective there are existing differences in higher education financing and regulatory environments across the different countries. Bolli (2011) is now 
producing some international comparisons of university production frontiers. However, the brief review presented here does not suggest that any inter-country conclusions can be derived regarding either operating efficiency or productivity changes. Rather, what the review clearly points out is the absence of any DEA study of the private for-profit sector and, perhaps more importantly, a comparison of productivity changes achieved among DMUs in that sector relative to the publicly owned institutional sector. And as Figueiredo de Franca, et al. (2010) discuss, DEA is applicable to both for-profit and non-profit units. The remainder of this paper proceeds to fill that gap with panel date DEA estimates of efficiency and productivity changes for two-year degree granting for-profit and public colleges in the U.S.

\section{Methodology}

In the present paper, DEA is used first to determine university operating efficiencies and second to determine productivity changes. For both, a university's efficiency or productivity can be measured as performance in using inputs to produce outputs. In the general DEA framework of multiple outputs and inputs, the efficiency performance for a DMU can be expressed in ratio form as

$$
\sum_{r=1}^{s} u_{r} y_{r o} / \sum_{i=1}^{m} v_{i} x_{i o}
$$

Here, the evaluated DMU or university as denoted by the " $o$ " subscript uses $x_{i}$ inputs, $i=1, \ldots, m$ in producing $y_{r}$ outputs, $r=1, \ldots, s$. The relative importance of inputs and outputs are determined according to the $u$ and $v$ weights. In this context, it is assumed that universities seek to obtain maximum operating efficiency.

The linear programming problem can be stated as an output-oriented or input-oriented envelopment model. An output-oriented model tends to be more appropriate in cases where resources are in fixed supply, while input-oriented models are better suited for instances in which fixed amounts of outputs need to be produced (Coelli, 1996). In applications to higher education, Agasisti and Johnes (2009) use an output orientation, while McMillan and Chan (2006) use an input-oriented model. However, in experimenting with alternatives, the latter authors find that the results are insensitive to model choice. In addition, as Coelli (1996) points out, both models estimate identical frontiers and, therefore, the same efficient DMUs; only inefficient DMUs could differ between the models. In the present research, it was confirmed that the productivity estimates were essentially identical under both models. Therefore, the output-oriented model was chosen based on the notion that university and college resource constraints tend to be more binding than fixed output targets.

Using standard notation (e.g., Cooper et al., 2004; Cook \& Zhu, 2008), the full model for observations on $j=1, \ldots$, $N$ universities can be specified as maximizing the following equation (2) subject to the constraints imposed by equations (3), (4), and (5):

$$
\begin{array}{rc}
\max _{\phi, \lambda} \phi & \\
\sum_{j=1}^{N} y_{r j} \lambda_{j}-\phi y_{r o} \geq 0 & \mathrm{r}=1, \ldots, s \\
x_{i o}-\sum_{j=1}^{N} x_{i j} \lambda_{j} \geq 0 & i=1, \ldots, m \\
\lambda_{j} \geq 0 & \mathrm{j}=1, \ldots, N
\end{array}
$$

The value $1 / \phi$ represents the technical efficiency score of the $j$ th DMU or college and the $\lambda$ 's are constants. The model assumes colleges operate under constant returns to scale (CRS) technology such that a proportional increase in inputs result in a proportional increase in outputs. This CRS model, also dubbed as CCR as due to Charnes, Cooper, and Rhodes (1978), is appropriate when all DMUs are operating at the long run optimal scale. Relaxing this assumption and allowing for variable returns to scale, VRS, or BCC as due to Banker, Charnes, and Cooper (1984), is accomplished with the requirement that the sum of the lamda equals the value one. Technical efficiencies of colleges under the CRS model will include scale efficiencies and therefore be smaller than technical efficiency estimates under the VRS model.

For a given DMU or college, the resulting technical efficiency score can range from zero to one depending on that college's "distance" from the efficient production frontier. Achieving a point on the frontier results in an efficiency score of one or $100 \%$ efficiency. Over time, changes in college operationg efficiencies can alter, for the better or worse, the distance from the frontier. In addition, the frontier can shift due to technological changes, thereby also changing a college's distance. The two effects determine the total productivity change occurring among colleges. Using panel data, productivity changes can be estimated using the Malmquist index (Malmquist, 
1953). The index can be computed as the distance $(D)$ of productivity in year $t+1$ relative to year $t$ (Fare et al., 1994). Decomposing the index into its individual components gives rise to the expression (e.g., Cooper et al., 2004; Cook \& Zhu, 2008).

$$
M_{0}\left(x^{t+1}, y^{t+1}, x^{t}, y^{t}\right)=\frac{D_{0}^{t+1}\left(x^{t+1}, y^{t+1}\right)}{D_{0}^{t}\left(x^{t}, y^{t}\right)}\left[\left(\frac{D_{0}^{t}\left(x^{t+1}, y^{t+1}\right)}{D_{0}^{t+1}\left(x^{t+1}, y^{t+1}\right)}\right)\left(\frac{D_{0}^{t}\left(x^{t}, y^{t}\right)}{D_{0}^{t+1}\left(x^{t}, y^{t}\right)}\right)\right]^{\frac{1}{2}}
$$

Efficiency changes are captured in the first term of (6) and can yet be further divided into changes created by pure technical or managerial efficiency and changes attributed to scale efficiency. Frontier shifts occur with respect to the second term embedding technology changes. For $M$ greater than one, total university productivity is increasing. Productivity regress is accompanied by $M$ being less than one. Productivity increases owing to technological improvements can be offset by declines in technical operating efficiencies that could potentially be due to the deterioration in managerial efficiency.

\section{Data}

The most comprehensive data pertaining to U.S. postsecondary educational institutions is maintained by the U.S. National Center for Education Statistics and made available through the Integrated Postsecondary Education Data System (IPEDS). From IPEDS, data are drawn for publicly owned and privately owned for-profit institutions having the same IPEDS Carnegie Classification and being accredited to offer two-year associate degrees but no higher level degree. Therefore, excluded are the many for-profit institutions offering one-year or less educational opportunities in vocational areas, e.g., culinary and truck driving schools or institutes. Thus, the sample of institutions will likely be appropriate in satisfying the homogeneity preferences of DEA. The data releases for academic years are considerably lagged and, in some instances, the reporting requirements alter the definition or availability of variables and consequently create difficulties for longitudinal analyses. For the present research it was possible to establish panel data for four academic years, 2005-06 through 2008-09. After deleting institutions that did not report any financial, credit hour, or enrollment data, a balanced panel remained for 737 publicly owned colleges and 127 privately owned for-profit colleges.

The data are somewhat limited in terms of what one would prefer to have available for defining college inputs and outputs. The measures chosen, however, do parallel those used in other DEA research reviewed in the previous section of this paper. However, none of those previous DEA studies investigated for-profit higher education and some of the data limitations associated with that sector. Yet, for college inputs it was possible to generate seven measures common to both public and private for-profit colleges; three relate to student inputs and four are connected to management. These are summarized in Table 1 along with their means and standard deviations. Annual, twelve month unduplicated headcount enrollment is the measure for student inputs. In an attempt to mirror some academic characteristics of students, the percent of students returning fall term from the previous fall term is included. In addition, included is the dollar amount of low-income federal grants received by students. That measure can account for the possible provision in meeting the financial needs of students but it could relate to student academic abilities if low-income recipients are entering postsecondary education from low-income underfunded school districts. The four inputs related to managerial decision making include the allocation of college expenditures to support instructional activities, the total value of college assets, the number of full-time faculty members employed, and the average faculty salary.

Both DEA studies and parametric studies of higher education have focused on research level universities and, therefore, multiproduct production that includes undergraduate and graduate education and research. In the present case of U.S. two-year colleges there is only the single output of undergraduate education. A small number of colleges do report contract and grant revenues that have been used as research proxies in other studies. However, because the vast majority of colleges report zero such revenues it would not be appropriate in the DEA analysis to include that output measure. Moreover, it is not likely to be of the academic type research associated with grant revenues at the university level. For educational output, previous studies have used either fall term student enrollments on the one hand or degrees awarded on the other. As somewhat of a compromise, but especially relevant to public universities in the U.S., the present measure of undergraduate education follows that used by Sav (2004) and Sav (2012) and is the full academic year of credit hour production. Unlike fall enrollment measures, this measure accounts for both part and full-time students registered for varying course loads and taking courses throughout the full academic year, including any intersessions and summer terms. Moreover, for the public colleges under the present study it is consistent with the government subsidy models under which colleges receive state supported revenues in return for credit hour production, not conferred degrees. In addition, conferred degrees would be more relevant in a student cohort framework but would not adequately 
capture production spikes occurring in relation to enrollment and credit hour increases during recessionary periods as is the case with the 2005-09 academic period presently under study.

As indicated in the Table 1, two-year public colleges compared to two-year private for-profit colleges produce approximately five times as many credit hours per academic year. However, that comes from more than twelve times as many students. The for-profits report a greater percentage of returning students, hence student retention. On all accounts, the dollar assets and instructional expenditures of publics far exceed that of the for-profits. In addition, the faculty employment is nearly seven times as large at publics compared to for-profits. In contrast, faculty salaries at public colleges are on average only thirty percent higher than faculty salaries at private for-profit colleges.

Table 1. College Input and Output Means and Standard Deviations

\begin{tabular}{lcccc}
\hline \multirow{2}{*}{ Variable } & \multicolumn{2}{c}{ Private-For-Profit } & \multicolumn{2}{c}{ Public } \\
\cline { 2 - 5 } & Mean & Std. Dev. & Mean & Std. Dev. \\
\hline Annual Unduplicated Enrollment, \# & 589 & 523 & 6,816 & 6,783 \\
Returning Students, \% & 64 & 16 & 57 & 9 \\
Low-Income Student Loans, \$ & $1.53 \mathrm{E}+06$ & $1.70 \mathrm{E}+06$ & $4.83 \mathrm{E}+06$ & $4.73 \mathrm{E}+06$ \\
Instructional Support, \$ & $2.28 \mathrm{E}+06$ & $2.95 \mathrm{E}+06$ & $1.84 \mathrm{E}+07$ & $1.74 \mathrm{E}+07$ \\
Institutional Assets, \$ & $1.03 \mathrm{E}+07$ & $2.17 \mathrm{E}+07$ & $4.83 \mathrm{E}+06$ & $4.73 \mathrm{E}+06$ \\
Faculty Employed, \# & 18 & 19 & 118 & 99 \\
Average Faculty Salary, \$ & 42,314 & 10,563 & 54,950 & 12,491 \\
Annual Credit Hour Production, \# & 27,130 & 27,594 & 135,115 & 132,692 \\
Observations, \# & 127 & 127 & 737 & 737 \\
\hline
\end{tabular}

\section{Results}

DEA estimates of college efficiencies are presented in Table 2. Both the CRS and VRS efficiencies are presented. Of course, the CRS efficiencies are smaller due to the fact that they contain scale inefficiencies. Thus, the last column of Table 2 is the scale efficiency, i.e., the ratio or the CRS to VRS efficiencies. Efficiencies are listed for each academic year. In addition, to account for production variability over time, results are also presented for efficiency estimates at college four-year output and input means.

Under both the CRS and VRS technology assumptions, the DEA results indicate that private for-profit colleges operate at greater efficiency than the publicly owned colleges. That result holds at the mean and median efficiency and in every academic year except 2007-08 where for-profit colleges experience an efficiency decrease. Public college efficiency also declines in that same academic year but the decline is not as severe. If those efficiency declines are in part due to the beginning of the effects of the financial crisis, then it appears that the for-profit sector of two-year colleges bore a greater burden than their publicly owned counterparts. The lesser effect experienced among public colleges may have been the result of some cushioning by already committed tax dollars and budget setting contractual commitments. For the VRS results, for-profit efficiencies are nearly all above $70 \%$ whereas public sector efficiencies struggle to get to $65 \%$ in any given academic year. When evaluated at the mean levels of production and input usage, more than a ten percentage point difference exists in inter-sector efficiency: for-profit colleges are approximately $77 \%$ efficient and public colleges are at $64 \%$ efficiency. Additionally, the percent of for-profit colleges that are efficient, i.e., having efficiency scores of 1.0, are almost four times that of public colleges under both the CRS and VRS measures; $15 \%$ vs. $4 \%$ in the CRS model and 32\% vs. 8\% in the VRS model.

The scale efficiency results in a given academic year are not of much difference between the two sectors. For further investigation, the returns to scale under which each college operates is determined through a comparison of technical efficiency under non-increasing returns to scale relative to variable returns to scale (Coelli, 1996). Table 2 reports the percent of colleges operating at decreasing, constant, and increasing returns to scale. Both sectors have nearly identical percentages of colleges operating at increasing returns to scale, thereby suggesting that there can be cost advantages in additional production expansion among a the majority of colleges. Cost disadvantages due to decreasing returns to scale and the absence of constant returns to scale is a more prevalent issue in the public compared to the private sector; e.g., $17 \%$ of public colleges are estimated to operate under decreasing returns compared to $5 \%$ of private colleges. Yet, the overwhelming presence of increasing returns to scale suggests that both college sectors could continue the expansion of production even beyond that which accompanied the recession.

Turning to the more powerful advantages enabled by the panel data, Table 3 provides the Malmquist results. Following the methodological decompositions noted earlier, the total factor productivity changes are presented 
along with its component parts beginning with the pure or managerial change and then the scale change. The latter two multiplicatively determine the efficiency change which is then followed by the frontier shift due to technological change.

Table 2. Results of DEA Efficiency Estimates

\begin{tabular}{lcccccc}
\hline & \multicolumn{3}{c}{ Private-For-Profit } & \multicolumn{3}{c}{ Public } \\
\cline { 2 - 7 } & CRS Model & VRS Model & Scale & CRS Model & VRS Model & Scale \\
\hline $2005-06$ & 0.608 & 0.712 & 0.871 & 0.388 & 0.435 & 0.915 \\
$2006-07$ & 0.729 & 0.788 & 0.932 & 0.587 & 0.638 & 0.929 \\
$2007-08$ & 0.379 & 0.566 & 0.718 & 0.581 & 0.634 & 0.924 \\
$2008-09$ & 0.703 & 0.749 & 0.945 & 0.608 & 0.653 & 0.936 \\
Mean & 0.670 & 0.773 & 0.873 & 0.591 & 0.644 & 0.925 \\
Median & 0.617 & 0.772 & 0.927 & 0.551 & 0.601 & 0.960 \\
Minimum & 0.112 & 0.304 & 0.112 & 0.222 & 0.231 & 0.383 \\
Maximum & 1 & 1 & 1 & 1 & 1 & 1 \\
Std. Dev. & 0.222 & 0.209 & 0.160 & 0.153 & 0.166 & 0.098 \\
Percent Efficient & $15 \%$ & $32 \%$ & $17 \%$ & $4 \%$ & $8 \%$ & $5 \%$ \\
Decreasing Returns & & & $5 \%$ & & & $17 \%$ \\
Constant Returns & & & $17 \%$ & & & $6 \%$ \\
Increasing Returns & & & $79 \%$ & & & $77 \%$ \\
\hline
\end{tabular}

Upon examination of the annual efficiency changes it becomes readily apparent that both private for-profit and public colleges experienced substantial variability across academic years. Most of the variability, however, is present with respect the large changes that occurred in the 2007-08 academic year and is concomitant with the beginning of the financial crisis induced recession. Within both sectors, there occurred fairly large 2007-08 efficiency losses (efficiency change scores $<1$ ) with respect to both managerial and scale efficiencies. That is in stark contrast to the large efficiency gains (scores exceeding 1.0) on both accounts of managerial and scale efficiencies in the previous 2006-07 and in the following 2008-09 academic years.

With regard to inter-sector comparisons, public colleges outperformed private for-profit colleges in the managerial efficiency improvements in both the 2006-07 and 2007-08 academic years. However, in the final 2008-09 academic year of analysis, private college managerial efficiency improvements overpower those attained in the public sector. On average, though, the for-profit managerial efficiency gain was 3.3\% compared to $16.8 \%$ among the public colleges. Compared to those managerial efficiency changes, nearly the opposite inter-sector changes occurred with respect to changes in scale efficiencies. That is, the mean scale efficiency change of 3.4\% among the for-profits exceeds that of $1.1 \%$ within the public college sector. At the mean scores, however, the results indicate that managerial and scale efficiency changes are approximately equal (1.033 and 1.034, respectively) in their contribution to the overall mean efficiency changes (1.064) achieved among private colleges. That balance in not present in the public college sector: managerial efficiency changes (1.168) compared to scale efficiency changes (1.011) are by far the largest contributor to the mean efficiency change (1.179).

As Table 3 indicates, it is these efficiency changes relative to technology changes that are responsible for the total factor productivity changes found among both private and public colleges.

In fact, as indicated in Table 3, in both sectors the results largely reflect technological regress, i.e., the mean technological change scores are 0.912 and 0.827 in the private and public sectors, respectively. The efficiency improvements partially but not fully offset that regress to yield the somewhat surprisingly total productivity decline of $3 \%$ in both sectors (i.e., scores of 0.971 and 0.970). Again, on an academic year basis, 2007-08 appears to be a possible effect of the financial crisis and the beginning of the recession. But the results indicate that the turmoil induced swift advances in the technology of producing higher education at the two-year college level. That is, compared to the 2006-07 academic year, there occurred a large bump in frontier shifts in 2007-08 for both college sectors but especially so in the private sector as noted by its 2.188 technical efficiency change. That, in fact, led to the only total factor productivity improvement on an academic year basis in either of the sectors.

The final three rows of Table 3 provide additional insights into the distribution of colleges with respect to efficiency changes. Examining the Malmquist total productivity change, 59\% of private colleges have productivity changes of less 1.0 or $100 \%$. In the public sector, that climbs to $75 \%$. The distributions confirm that the overall regress is due to the large percentage of colleges having less that $100 \%$ technological advancements; 
in the private sector $90 \%$ of colleges fall below 1.0 while in the public sector $99 \%$ are in that end of the distribution. Thus, again it is the efficiency improvements that serve to offset the lack of technology improvements, i.e., $66 \%$ of private colleges and $96 \%$ of public colleges managed efficiency improvements exceeding $100 \%$.

Table 3. Results of Malmquist Efficiency and Productivity Change Estimates

\begin{tabular}{|c|c|c|c|c|c|}
\hline & Mgt & Scale & Eff & Tech & Total \\
\hline \multicolumn{6}{|l|}{ For-Profit Colleges } \\
\hline $2006-07$ & 1.137 & 1.045 & 1.188 & 0.781 & 0.928 \\
\hline 2007-08 & 0.635 & 0.728 & 0.462 & 2.188 & 1.011 \\
\hline 2008-09 & 1.486 & 1.437 & 2.135 & 0.434 & 0.927 \\
\hline Mean & 1.033 & 1.034 & 1.064 & 0.912 & 0.971 \\
\hline Median & 1.017 & 1.011 & 1.064 & 0.923 & 0.969 \\
\hline Minimum & 0.682 & 0.585 & 0.585 & 0.331 & 0.296 \\
\hline Maximum & 1.931 & 1.439 & 2.069 & 1.070 & 1.818 \\
\hline Std. Dev. & 0.144 & 0.088 & 0.152 & 0.096 & 0.173 \\
\hline Percent $<1$ & $28 \%$ & $26 \%$ & $28 \%$ & $90 \%$ & $59 \%$ \\
\hline Percent = 1 & $18 \%$ & $9 \%$ & $6 \%$ & $0 \%$ & $0 \%$ \\
\hline Percent > 1 & $54 \%$ & $65 \%$ & $66 \%$ & $10 \%$ & $41 \%$ \\
\hline \multicolumn{6}{|l|}{ Public Colleges } \\
\hline $2006-07$ & 1.526 & 1.02 & 1.556 & 0.618 & 0.961 \\
\hline 2007-08 & 0.995 & 0.995 & 0.99 & 0.982 & 0.972 \\
\hline 2008-09 & 1.033 & 1.015 & 1.049 & 0.925 & 0.97 \\
\hline Mean & 1.168 & 1.011 & 1.179 & 0.827 & 0.970 \\
\hline Median & 1.155 & 1.003 & 1.167 & 0.835 & 0.967 \\
\hline Minimum & 0.808 & 0.854 & 0.793 & 0.648 & 0.561 \\
\hline Maximum & 1.715 & 1.515 & 1.710 & 1.037 & 1.385 \\
\hline Standard Deviation & 0.125 & 0.043 & 0.121 & 0.063 & 0.067 \\
\hline Percent $>1$ & $5 \%$ & $36 \%$ & $4 \%$ & $100 \%$ & $75 \%$ \\
\hline Percent $=1$ & $2 \%$ & $4 \%$ & $0 \%$ & $0 \%$ & $1 \%$ \\
\hline Percent $>1$ & $93 \%$ & $60 \%$ & $96 \%$ & $0 \%$ & $24 \%$ \\
\hline
\end{tabular}

Note: Technical Efficiency Change (Eff) = Management Efficiency Change (Mgt) x Scale. Efficiency Change (Scale) and Total Productivity Change $($ Total $)=$ Eff $x$ Technological Change $($ Tech $)$.

\section{Conclusions}

This paper set out to investigate and compare the efficiency and productivity changes of private for-profit colleges to that of publicly owned and operated colleges. That was accomplished using panel data covering the 2005-09 academic years for two-year degree granting colleges in the U.S. Data envelopment analysis (DEA) was employed to estimate annual operating efficiencies under both constant and variable returns to scale models and to determine scale efficiencies. Panel data further enabled the estimation and comparison of inter-sector productivity changes via the Malmquist index and a decomposition of such changes into that which could be attributed to managerial, scale, efficiency, and technological changes. Given the academic years included in the analysis, the paper sought to offer some insights into the possible effects on colleges of the financial crisis.

The paper offers the following general observations:

- Compared to publicly owned two-year degree granting colleges, private for-profit colleges achieved higher operating efficiencies over the 2005-09 academic years. That was found to hold under both returns to scale models. Under variable returns to scale, $32 \%$ of for-profit colleges were efficient compared to $8 \%$ in the public sector.

- Both sectors experienced efficiency decreases that accompanied the beginning to the financial crisis in the 2007-08 academic year. However, the for-profit sector experienced a substantially larger impact.

- The proportion of colleges operating under increasing returns to scale technology was essentially the same at $77 \%$ to $79 \%$ in both sectors, thereby indicating that both may have cost advantages with respect to increased production.

- Results from decomposition of the Malmquist index indicated that both sectors, on average, experienced managerial, as well as scale, efficiency improvements. Among private colleges, those two gains were balanced at $3.3 \%$ on average. Among publics, the managerial gain of nearly $17 \%$ far exceeded the $1.1 \%$ scale 
improvement.

- Efficiency improvements present in both sectors were hampered by technological regress as evidenced by a mean index of 0.912 among private colleges and 0.827 among public colleges.

- Thus, overall productivity declined in both college sectors. Interestingly, the decline was identical with an overall Malmquist index of 0.97 or 3\% fall in productivity.

- The results indicate instability associated with the 2007-08 academic year. In fact, countering the above, operating efficiency took a dramatic fall while technological change reversed course. The latter was strong enough among private for-profit colleges to overpower the efficiency decline and produce the only annual productivity gain for either sector. That productivity gain amounted to $1.1 \%$.

Comparing the results presented here to the three existing DEA longitudinal studies, there are obvious differences in the one means of comparison, viz., productivity changes. The most recent of those three studies find productivity gains of 9.4\% and 8.5\% among Italian and English universities (Agasisti \& Johnes, 2009). Those productivities, however, are for the 2001-04 academic years and, therefore, completely predate the financial crisis. In addition they include universities producing graduate education and research but do not allow for differences in ownership structures, in particular the entry of for-profits into higher education. Thus, the present study is believed to be the first to provide DEA efficiency and productivity comparisons between private for-profit and public institutions of higher education and to include academic years that offer potential insights into the efficiency and productivity changes brought about by the financial crisis. It is hoped that future research can focus on (1) determining the extent to which higher education institutions in other countries responded to and were affected by the financial crisis and (2) the effects of the growing international presence of for-profit colleges and universities and its relevance to the public provision of higher education. Of course, the extent to which the for-profit and public differences or lack thereof found herein are sustainable is critically dependent upon future academic years of production and management and, therefore, research.

\section{References}

Agasisti, T., \& Johnes, G. (2009). Beyond frontiers: comparing the efficiency of higher education decision-making units across more than one country. Education Economics, 17(1), 59-79. http://dx.doi.org/10.1080/09645290701523291

Ahn, T., Charnes, A., \& Cooper, W. W. (1988). Some statistical and DEA evaluations of relative efficiencies of public and private institutions of higher learning. Socio-Economic Planning Sciences, 22(6), 259-269. http://dx.doi.org/10.1016/0038-0121(88)90008-0

Athanassopoulos, A. D., \& Shale, E. (1997). Assessing the comparative efficiency of higher education institutions in the UK by means of data envelopment analysis. Education Economics, 5(2), 117-134. http://dx.doi.org/10.1080/09645299700000011

Avkiran, N. K. (2001). Investigating technical and scale efficiencies of Australian Universities through data envelopment analysis. Socio-Economic Planning Sciences, $\quad 35(1), \quad 57-80$. http://dx.doi.org/10.1016/S0038-0121(00)00010-0

Banker, R. D., Charnes, A., \& Cooper, W. W. (1984). Some models for estimating technical and scale inefficiencies in data envelopment analysis. Management Science, 30, 1078-1092. http://dx.doi.org/10.1287/mnsc.30.9.1078

Beasley, J. E. (1990). Comparing university departments. Omega, 18(2), $171-183$. http://dx.doi.org/10.1016/0305-0483(90)90064-G

Beasley, J. E. (1995). Determining teaching and research efficiencies. Journal of the Operational Research Society, 46(4), 441-452. http://dx.doi.org/10.2307/2584592

Bolli, T. (2011). The gloval production frontier of universities. KOF Working Papers, Meeting SSES 2011, Lucerne, Switzerland, June 10, 1-15.

Breu, T. M., \& Raab, R. L. (1994). Efficiency and perceived quality of the nation’s ‘top 25’ National Universities and National Liberal Arts Colleges: An application of data envelopment analysis to higher education. Socio-Economic Planning Sciences, 28(1), 33-45. http://dx.doi.org/10.1016/0038-0121(94)90023-X

Castano, M. C., \& Cabanda, E. (2007). Sources of efficiency and productivity growth in the Philippine state universities and colleges: a non-parametric approach. International Business and Economics Research Journal, 6(6), 79-90.

Casu, B., \& Thanassoulis, E. (2006). Evaluating cost efficiency in central administrative services in UK 
universities. Omega, 34(5), 417-426. http://dx.doi.org/10.1016/j.omega.2004.07.020

Caves, D. W. (1982). Multilateral comparisons of output, input, and productivity using superlative index numbers. Economic Journal, 92(4), 73-86. http://dx.doi.org/10.2307/2232257

Charnes, A., Cooper, W. W., \& Rhodes, E. (1978). Measuring the efficiency of decision making units. European Journal of Operational Research, 2(6), 425-444. http://dx.doi.org/10.1016/0377-2217(78)90138-8

Cobert, A., Levary, R. R., \& Shaner, M. C. (2000). Determining the relative efficiency of MBA programs using DEA. European Journal of Operational Research, 125(3), 656-669. http://dx.doi.org/10.1016/S0377-2217(99)00275-1

Coelli, T. (1996). A guide to DEAP version 2.1: A data envelopment analysis (Computer) program. Working Paper Center for Efficiency and Productivity Analysis. Department of Economics University of New England.

Cook, W. D., \& Zhu, J. (2008). Data Envelopment Analysis.

Cooper, W. W., Seiford, L. M., \& Zhu, J. (2004). Handbook on Data Envelopment Analysis. Boston: Kluwer Academic Publishers.

Fare, R., Grosskopf, S., Norris, M., \& Zhang, Z. (1994). Productivity growth, technical progress, and efficiency changes in industrialized countries. American Economic Review, 84, 66-83.

Figueiredo de Franca, J. M., de Figueiredo, J. N., \& Lapa, J. d. S. (2010). A DEA methodology to evaluate the impact of information asymmetry on the efficiency of not-for-profit organizationa with an application to higher educationin Brazil. Annuals of Operations Research, 173, 39-56. http://dx.doi.org/10.1007/s10479-009-0536-1

Glass, J. C., McCallion, G., McKillop, D. G., Rasarantnam, S., \& Stringer, K. S. (2006). Implications of variant efficiency measures for policy evaluations in UK higher education. Socio-Economic Planning Sciences, 40(2), 119-142. http://dx.doi.org/10.1016/j.seps.2004.10.004

Johnes, J. (2004). Efficiency measurement. In G. Johnes and J. Johnes (Eds.), International Handbook on the Economics of Education (pp. 613-670). Cheltenham, UK: Edward Elgar.

Korhonen, P., Tainio, R., \& Wallenius, J. (2001). Value efficiency analysis of academic research. European Journal of Operational Research, 130(2001), 121-132. http://dx.doi.org/10.1016/S0377-2217(00)00050-3

Koshal, R., \& Koshal, M. (1999). Economies of scale and scope in higher education: A case of comprehensive $\begin{array}{lllll}\text { universities. } & \text { Economics } & \text { 269-277. }\end{array}$ http://dx.doi.org/10.1016/S0272-7757(98)00035-1

Leitner, K-H., Prikoszovits, J., Schaffhauser-Linzatti, M., Stowasser, R., \& Wagner, K. (2007). The impact of size and specialization on universities' department performance: a DEA analysis applied to Austrian universities. Higher Education, 53, 517-538. http://dx.doi.org/10.1007/s10734-006-0002-9

Malmquist, S. (1953). Index numbers and indifference surfaces. Trabajos de Estatistica, 4, 209-242. http://dx.doi.org/10.1007/BF03006863

McMillan, M. L., \& Chan, W. H. (2006). University efficiency: A comparison and consolidation of results from stochastic and non-stochastic methods. Education Economics, 14, 1-30. http://dx.doi.org/10.1080/09645290500481857

Reichmann, G. (2004). Measuring university library efficiency using data envelopment analysis. Libri, 54(2), 136-146. http://dx.doi.org/10.1515/LIBR.2004.136

Sav, G. T. (2004). Higher education costs and scale and scope economies. Applied Economics, 36(2), 607-614. http://dx.doi.org/10.1080/0003684042000217643

Sav, G. T. (2012). Managing operating efficiencies of publicly owned universities: American university stochastic frontier estimates using panel data. Advances in Applied Economics and Management, 2(1), 1-23.

Sinuany-Stern, Z., Mehrez, A., \& Barboy, A. (1994). Academic departments efficiency via DEA. Computers and Operations Research, 21(5), 543-556. http://dx.doi.org/10.1016/0305-0548(94)90103-1

Worthington, A. C., \& Lee, B. L. (2008). Efficiency, technology and productivity change in Australian universities, 1998-2003. Economics of Education Review, 27(3), 285-298. http://dx.doi.org/10.1016/j.econedurev.2006.09.012 